Multiderivative methods for

periodic initial value problems

E.H. Twizell

and

A.Q.M. Khaliq 
0. $\underline{\text { Abstract }}$

A family of two-step multiderivative methods based on Pade approximants to the exponential function is developed. The methods are analysed and periodicity intervals in PECE mode are calculated.

Two of the methods are tested on two problems from the literature and one predictor-corrector combination is tested on two further problems. 


\section{Development of the methods}

Consider the second order initial value problem

$$
{\underset{\sim}{\mathrm{y}}}^{\prime \prime}(\mathrm{t})=\underset{\sim}{\mathrm{f}}(\mathrm{t}, \underset{\sim}{\mathrm{y}}) ; \underset{\sim}{\mathrm{y}}\left(\mathrm{t}_{0}\right)={\underset{\sim}{\mathrm{y}}}_{0}, \underset{\sim}{\mathrm{y}^{\prime}}\left(\mathrm{t}_{0}\right)={\underset{\sim}{\mathrm{y}}}_{0}^{\prime}
$$

Where $y \varepsilon E^{N}$. A particular case of (1) is the linear problem

$$
\mathrm{y}_{\sim}^{\prime \prime}(\mathrm{t})=\mathrm{A} \underset{\sim}{\mathrm{y}}(\mathrm{t})+\underset{\sim}{\mathrm{B}} ; \underset{\sim}{\mathrm{y}}\left(\mathrm{t}_{0}\right)=\underset{\sim}{\mathrm{y}_{0}}, \underset{\sim}{\mathrm{y}^{\prime}}\left(\mathrm{t}_{0}\right)={\underset{\sim}{\mathrm{y}}}_{0}^{\prime} .
$$

Equation (2) arises in the numerical solution of the simple wave

equation $\partial^{2} \mathrm{u} / \partial \mathrm{t}^{2}=\partial^{2} \mathrm{u} / \partial \mathrm{x}^{2}$ when the space derivative is approximated by a finite difference replacement such as

$$
\frac{\partial^{2}}{\partial x^{2}}=h^{-2}\{u(x-h, t)-2 u(x, t)+u(x+h, t)\}+0\left(h^{2}\right)
$$

where $\mathrm{h}$ is the increment in $\mathrm{x}$ arising from the space discretization. This leads to a system of ordinary differential equations of the form (2) in which the diagonalizable matrix A has real, negative eigenvalues, and $\underset{\sim}{\mathrm{B}} \equiv \underset{\sim}{0}$ when the boundary conditions are zero.

It is therefore appropriate to consider the single test equation

$$
y^{\prime \prime}(t)=-\lambda^{2} y(t) \quad ; y\left(t_{0}\right)=y_{0}, y\left(t_{0}\right)=y_{0}^{\prime}
$$

where $\lambda, \mathrm{y} \in \mathbb{R}$, whose general solution

$$
y(t)=a \cos \lambda t+b \sin \lambda t
$$

is periodic with period $2 \pi / \lambda$ for all $a, b$ other than the trivial case $\mathrm{a}=\mathrm{b}=0$.

The general solution (5) may be written in the alternate form

$$
u(t)=a \exp (i \lambda t)+b \exp (-i \lambda t), \quad i=+\sqrt{-1}
$$

which becomes 
$\mathrm{y}(\mathrm{t})=-\frac{1}{2} \mathrm{i}\left(\mathrm{iy}_{0}+\lambda^{-1} \mathrm{y}_{0}^{\prime}\right) \exp \left\{\mathrm{i} \lambda\left(\mathrm{t}-\mathrm{t}_{0}\right)\right\}-\frac{1}{2} \mathrm{i}\left(\mathrm{iy}_{0}-\lambda^{-1} \mathrm{y}_{0}^{\prime}\right) \exp \left\{-\mathrm{i} \lambda\left(\mathrm{t}-\mathrm{t}_{0}\right)\right\}$

when the initial conditions in (4) are introduced.

It may now be shown that $y(t)$ given in (7) satisfies the recurrence relation

$$
y(t+\ell)-\{\exp (i \ell \lambda)+\exp (-i \ell \lambda)\} y(t)+y(t-\ell)=0
$$

where $\ell$ is a convenient increment in $t$. This recurrence relation may be used for $\mathrm{t}=\mathrm{t}_{0}+\ell, \mathrm{t}_{0}+2 \ell, \ldots$; for $\mathrm{t}=\mathrm{t}_{0}$ the initial conditions give $\mathrm{y}\left(\mathrm{t}_{0}\right)=\mathrm{y}_{0}^{\prime}$. but the value $\mathrm{y}\left(\mathrm{t}_{0},+\ell\right)$ remains to be determined in terms of $y_{0}$ and $y_{0}^{\prime}$. Equation (8) leads to a family of multiderivative methods for the solution of (1), the higher derivatives being easy to calculate because of the periodic properties of the problem.

Any numerical solution of (8) will determine $y(t)$ explicitly or implicitly depending on the approximations to exp $( \pm \mathrm{i} \ell \lambda)$. Using the $(\mathrm{m}, \mathrm{k})$ Padé approximent to exp (i $\ell \lambda)$ of the form

$$
\exp (\mathrm{i} \ell \lambda)=\mathrm{P}_{\mathrm{k}}(\mathrm{i} \ell \lambda) / \mathrm{Q}_{\mathrm{m}}(\mathrm{i} \ell \lambda)+0\left(\ell^{\mathrm{m}+\mathrm{k}+1}\right)
$$

where $P_{k}, Q_{m}$ are polynomials of degree $k, m$ respectively, defined by

$$
\mathrm{P}_{\mathrm{k}}(\theta) 1+\mathrm{p}_{1} \theta+\mathrm{p}_{2} \theta^{2}+\ldots \ldots+\mathrm{P}_{\mathrm{k}} \theta^{\mathrm{k}} ; \mathrm{p}_{0}(\theta) \equiv 1
$$

and

$$
\mathrm{Q}_{\mathrm{m}}\left(\theta \theta=1-\mathrm{q}_{1} \theta+\mathrm{q}_{2} \theta^{2}-\ldots . .+(-1)^{\mathrm{m}} \mathrm{q}_{\mathrm{m}} \theta^{\mathrm{m}} ; \mathrm{Q}_{0}(\theta \theta \equiv 1\right.
$$

With $\mathrm{p}_{1}>\mathrm{p}_{2}>\ldots . .>\mathrm{p}_{\mathrm{k}}>0$ and $\mathrm{q}_{1}>\mathrm{q}_{2}>\ldots . .>\mathrm{q}_{\mathrm{m}}>0$ depending on the chosen padé approximant, equation (8) takes the form

$$
\begin{gathered}
\mathrm{Q}_{\mathrm{m}}(\mathrm{i} \ell \lambda) \mathrm{Q}_{\mathrm{m}}(-\mathrm{i} \ell \lambda) \mathrm{y}(\mathrm{t}+\ell)-\left\{\mathrm{Q}_{\mathrm{m}}(-\mathrm{i} \ell \lambda) \mathrm{P}_{\mathrm{k}}(\mathrm{i} \ell \lambda)+\mathrm{Q}_{\mathrm{m}}(\mathrm{i} \ell \lambda) \mathrm{P}_{\mathrm{k}}(-\mathrm{i} \ell \lambda)\right\} \mathrm{y}(\mathrm{t}) \\
+\mathrm{Q}_{\mathrm{m}}(\mathrm{i} \ell \lambda) \mathrm{Q}_{\mathrm{m}}(-\mathrm{i} \ell \lambda) \mathrm{y}(\mathrm{t}-\ell)=0 .
\end{gathered}
$$


On substituting for the polynomials $\mathrm{P}_{\mathrm{k}}, \mathrm{Q}_{\mathrm{m}}$ in (12), odd powers of $i \ell \lambda$ vanish and the recurrence relation takes the form

$$
\begin{gathered}
\left\{1-\mathrm{a}_{1} \ell^{2} \lambda^{2}+\mathrm{a}_{2} \ell^{4} \lambda^{4}-\ldots .+(-1)^{\mathrm{m}} \mathrm{a}_{\mathrm{m}} \ell^{2 \mathrm{~m}_{\lambda} 2 \mathrm{~m}_{3}}\right\} \mathrm{y}(\mathrm{t}+\ell) \\
-\left\{2-\mathrm{b}_{1} \ell^{2} \lambda^{2}+\mathrm{b}_{2} \ell^{4} \lambda^{4}-\ldots+(-1)^{\mathrm{s}} \mathrm{b}_{\mathrm{s}} \ell^{2^{\mathrm{s}}} \lambda^{2 \mathrm{~s}}\right\} \mathrm{y}(\mathrm{t}) \\
+\left\{1-\mathrm{a}_{1} \ell^{2} \lambda^{2}+\mathrm{a}_{2} \ell^{4} \lambda^{4}-\ldots \ldots+(-1)^{\mathrm{m}} \mathrm{a}_{\mathrm{m}} \ell^{2 \mathrm{~m}_{\lambda} 2 \mathrm{~m}}\right\} \mathrm{y}(\mathrm{t}-\ell)=0,
\end{gathered}
$$

where the $a_{j} ., b_{j}$ clearly depend on the Padé approximant being used and $\mathrm{s}=\left[\frac{1}{2}(\mathrm{~m}+\mathrm{k})\right]$.

For a single equation of the form (1), equation (13) yields the twostep multiderivative formula

$$
\begin{aligned}
& \mathrm{y}_{\mathrm{n}+1}+\mathrm{a}_{1} \ell^{2} \mathrm{y}_{\mathrm{n}+1}^{\prime \prime}+\mathrm{a}_{2} \ell^{4} \mathrm{y}_{\mathrm{n}+1}^{(\mathrm{iv})}+\ldots \ldots \ldots+\mathrm{a}_{\mathrm{m}} \ell^{2 \mathrm{~m}_{\mathrm{y}_{\mathrm{n}+}}^{(2 \mathrm{~m})}} \\
& =2 \mathrm{y}_{\mathrm{n}}+\mathrm{b}_{1} \ell^{2} \mathrm{y}_{\mathrm{n}}^{\prime \prime}+\mathrm{b}_{2} \ell^{4} \mathrm{y}_{\mathrm{n}}^{(\mathrm{iv})}+\ldots \ldots \ldots+\mathrm{b}_{\mathrm{s}} \ell^{2 \mathrm{~s}_{\mathrm{y}_{\mathrm{n}}}(2 \mathrm{~s})}
\end{aligned}
$$

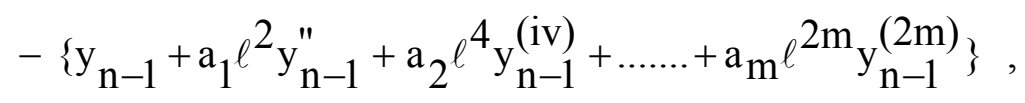

$\mathrm{n}=1,2, \ldots$, which is explicit of $\mathrm{m}=0$ and implicit if $\mathrm{m} \neq 0$. It is assumed that $y(t)$ is sufficiently often differentiable. In (14), $y_{j} \equiv y\left(t_{j}\right)=y\left(t_{0}+j \ell\right)$, where $j=0,1,2, \ldots$.

The non-zero coefficients of (14) for the algorithms yielded by the first sixteen entries of the Padé table are given in [7] and are reproduced in the Appendix.

Initial value problems for which $\underset{\sim}{\mathrm{f}}=\underset{\sim}{\mathrm{f}}(\mathrm{t}, \underset{\sim}{\mathrm{y}}, \underbrace{\prime}_{\sim})$ may clearly be written in the form of a first order system $\underset{\sim}{\mathrm{u}^{\prime}}=\underset{\sim}{\mathrm{v}}, \underset{\sim}{\mathrm{v}^{\prime}}=\underset{\sim}{\mathrm{f}}(\mathrm{t}, \underset{\sim}{\mathrm{u}}, \underset{\sim}{\mathrm{v}})$ where $\underset{\sim}{\mathrm{u}}=\underset{\mathcal{V}}{\mathrm{y}}, \underset{\sim}{\mathrm{v}}=\mathrm{y}^{\prime}$. Multiderivative methods for first order systems were discussed by the authors in [9]. 


\section{Analyses}

With the multiderivative method (14) may be associated with the linear difference operator L defined by

$$
\begin{array}{r}
L[y(t) ; \ell]=y(t+\ell)-2 y(t)+y(t-\ell)+\sum_{j=1}^{m} a_{j} \ell^{2 j} y^{(2 j)}(t+\ell) \\
-\sum_{W=1}^{S} b_{w} \ell^{2 w} y(2 w)(t)+\sum_{j=1}^{m} a_{j} \ell^{2 j} y(2 j)(t-\ell)
\end{array}
$$

Expanding $\mathrm{y}(\mathrm{t}+\ell)$ and $\mathrm{y}(\mathrm{t}-\ell)$ and their derivatives as Taylor series about $\mathrm{t}$, and gathering terms, gives

$$
\mathrm{L}[\mathrm{y}(\mathrm{t}) ; \ell]=\mathrm{C}_{0} \mathrm{y}(\mathrm{t})+\mathrm{C}_{1} \ell \mathrm{y}^{\prime}(\mathrm{t})+\mathrm{C}_{2} \ell^{2} \mathrm{y}^{\prime \prime}(\mathrm{t})+\ldots .
$$

where the $C_{j}$ are constants. The operator $L$ and the associated multiderivative method (14) are of order $\mathrm{p}$ if, in (16), $\mathrm{C}_{0}=\mathrm{C}_{1}=\ldots$ $=\mathrm{c}_{\mathrm{p}+1}=0$ and $\mathrm{c}_{\mathrm{p}+2} \neq 0$.

The term $\mathrm{C}_{\mathrm{p}+2}$ is the error constant of the multiderivative method (14); the error constants for the first 16 methods of the family are contained in the Appendix. The multiderivative method (14) is consistent with the differential equation if $\mathrm{p} \geq 1$; clearly the methods based on the $(0,1)$ and $(1,0)$ Padé approximants are inconsistent whilst all others are consistent.

Rearranging (14).in the form

$$
\begin{aligned}
& y_{n+1}-2 y_{n}+y_{n-1}=\sum_{j=1}^{v} \ell^{2 j_{(}}\left(-a_{j} y_{n+1}^{2 j}\right)+b_{j} y_{n}^{(2 j)}-a_{j} y_{n-1}^{(2 j)}, \\
& \text { where } v=\max (m, s)\left(\text { clearly for } m>k, b_{s+1}=\ldots=b_{v}=0\right. \text {, and for }
\end{aligned}
$$


$\mathrm{m}<\mathrm{k}, \mathrm{a}_{\mathrm{m}+1}=. .=\mathrm{a}_{\mathrm{v}}=0$ ), it is seen that the multiderivative methods are generated by the characteristic polynomials

$$
\rho(r)=r^{2}-2 r+1, \quad \sigma_{j}(r)=-a_{j} r^{2}+b_{j}-a_{j}
$$

for $\mathrm{j}=1, \ldots, \mathrm{v}$. The quadratic polynomial equation $\rho(\mathrm{r})=0$ has a double zero at $r=+1$ and the family of multiderivative methods is zerostable; all except the methods based on the $(0,1)$ and $(1,0)$ Padé approximants are thus convergent.

It is easy to see from (14) and (17) that, for m less than, equal to, or greater than $\mathrm{k}$, every member of the family of multiderivative methods is symmetric with even stepnumber (two-steps) and even order p. The findings of Lambert and Watson [4] on the periodicity of linear multistep method then carry over to multiderivative methods, as does the theory of weak stability (Lambert [3, p.202]).

Writing $\mathrm{H}=\ell \lambda$, equation (13) becomes

$$
\begin{aligned}
& \left\{1-\mathrm{a}_{1} \mathrm{H}^{2}+\mathrm{a}_{2} \mathrm{H}^{4-} \ldots+(-1)^{\mathrm{m}} \mathrm{a}_{\mathrm{m}} \mathrm{H}^{2 \mathrm{~m}}\right\} \mathrm{y}_{\mathrm{n}+1}-\left\{2-\mathrm{b}_{1} \mathrm{H}^{2}+\mathrm{b}_{2} \mathrm{H}^{4-} \ldots+(-1)^{\mathrm{s}} \mathrm{b}_{\mathrm{s}} \mathrm{H}^{2 \mathrm{~s}}\right\} \mathrm{y}_{\mathrm{n}}
\end{aligned}
$$

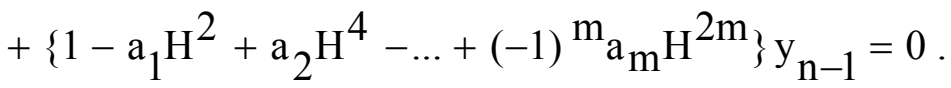

The solution of (19) involves the $n^{\text {th }}$ power of the zeros $r_{1}$ and $r_{2}$ of the periodicity polynomial

$$
\begin{aligned}
& \Omega\left(r, \mathrm{H}^{2}\right)=\left\{1-\mathrm{a}_{1} \mathrm{H}^{2}+\mathrm{a}_{1} \mathrm{H}^{4}-\ldots+(-1)^{\mathrm{m}_{\mathrm{a}}} \mathrm{a}_{\mathrm{m}} \mathrm{H}^{2 \mathrm{~m}_{3}} \mathrm{r}^{2}\right. \\
& -\left\{2-\mathrm{b}_{1} \mathrm{H}^{2}+\mathrm{b}_{2} \mathrm{H}^{4}-\ldots+(-1)^{\mathrm{s}} \mathrm{b}_{\mathrm{s}} \mathrm{H}^{2 \mathrm{~s}}\right\} \mathrm{r} \\
& +\left\{1-\mathrm{a}_{1} \mathrm{H}^{2}+\mathrm{a}_{2} \mathrm{H}^{4}-\ldots+(-1)^{\mathrm{m}_{\mathrm{a}}} \mathrm{a}_{\mathrm{m}} \mathrm{H}^{2 \mathrm{~m}_{3}},\right. \\
& =\mathrm{Q}_{\mathrm{m}}(-\mathrm{iH}) \mathrm{Q}_{\mathrm{m}}(\mathrm{iH}) \mathrm{r}^{2}-\left\{\mathrm{Q}_{\mathrm{m}}(-\mathrm{iH}) \mathrm{P}_{\mathrm{k}}(\mathrm{iH})+\mathrm{Q}_{\mathrm{m}}(\mathrm{iH}) \mathrm{P}_{\mathrm{k}}(-\mathrm{iH})\right\} \mathrm{r} \\
& +\mathrm{Q}_{\mathrm{m}}(-\mathrm{iH}) \mathrm{Q}_{\mathrm{m}}(\mathrm{iH}) \text {. }
\end{aligned}
$$


The interval of periodicity of the multiderivative method (14) is determined by computing the values of $\mathrm{H}^{2}$ for which the zeros of the periodicity equation

$$
\Omega\left(r, H^{2}\right)=0
$$

Satisfy

$$
r_{1}=e^{i \theta \theta(H)}, \quad r_{2}=e^{-i \theta \theta(H)}
$$

where $\theta(\mathrm{H}) \in \mathrm{R}$; the multiderivative method is then orbitally stable. For each member of the family of multiderivative methods, the periodicity equation may be written down in terms of the associated Padé approximant. Those multiderivative methods which have interval of periodicity $\mathrm{H}^{2} \in(0, \infty)$ are said to be P-stable (Lambert and Watson [4, p.199]). The intervals of periodicity for the consistent multiderivative methods based on the first 16 entries of the Padé table are contained in the Appendix (those interval bounds occurring as integers or improper fractions are exact, those occurring with one decimal place have been rounded up or down depending on whether the number is a lower or upper bound of the interval). The consistent multiderivative formulas based on those $(\mathrm{m}, \mathrm{k})$ Padé approximants for which $\mathrm{m} \geq \mathrm{k}$ are seen to be P-stable.

In computing the solution at time $\mathrm{t}=\ell$ the formula

$$
\mathrm{y}_{1}=\mathrm{y}_{0}+\ell \mathrm{y}_{0}^{\prime}+\frac{1}{3} \ell^{2} \mathrm{y}_{0}^{\prime \prime}+\frac{1}{6} \ell^{2} \mathrm{y}_{1}^{\prime \prime}-\frac{1}{18} \ell^{4} \mathrm{y}_{0}^{\left({ }^{(v)}\right.}+\frac{1}{72} \ell^{4} \mathrm{y}_{1}^{(\mathrm{vi})}+0\left(\ell^{5}\right)
$$

or the formula

$$
\begin{aligned}
\mathrm{y}_{1}=\mathrm{y}_{0}+\ell \mathrm{y}_{0}^{\prime} & +\frac{1}{3} \ell^{2} \mathrm{y}_{0}^{\prime \prime}+\frac{1}{6} \ell^{2} \mathrm{y}_{1}^{\prime \prime}-\frac{1}{45} \ell^{4} \ell_{0}^{(\mathrm{iv})}-\frac{7}{360} \ell^{4} \mathrm{y}_{1}^{(\mathrm{iv})} \\
& +\frac{1}{108} \ell^{6} \mathrm{y}_{0}^{(\mathrm{vi})} \frac{11}{-2160} \ell^{6} \mathrm{y}_{1}^{(\mathrm{vi})}+0\left(\ell^{7}\right)
\end{aligned}
$$

(Twizell [8]) may be used in solving problems which are known to have outward-spiralling theoretical solutions. Otherwise, Taylor's series 
may be used to give $\mathrm{y}_{1}$ to the necessary accuracy.

\section{Numerical examples}

Two of the family of multiderivative methods developed in section 1 were tested on two problems well known in the literature.

\section{$\underline{\text { Problem } 1}$}

This is the almost periodic problem introduced by Stiefel and Bettis [6] and considered by Lambert and Watson [4] and Cash [1]. It is given by

$$
z^{\prime \prime}=-z+0.001 \mathrm{e}^{\mathrm{it}} ; \mathrm{z}(0)=1, \quad \mathrm{z}^{\prime}(0)=0.9995 \mathrm{i}, \quad \mathrm{z} \in \mathrm{C} .
$$

The theoretical solution satisfies

$$
\begin{aligned}
& \mathrm{u}(\mathrm{t})=\cos \mathrm{t}+0.0005 \mathrm{t} \sin \mathrm{t}, \quad \mathrm{u} \in \mathbb{R}, \\
& \mathrm{v}(\mathrm{t})=\sin \mathrm{t} \quad-0.0005 \mathrm{t} \quad \cos \mathrm{t}, \quad \mathrm{v} \in \mathbb{R} \\
& \mathrm{z}(\mathrm{t})=\mathrm{u}(\mathrm{t})+\mathrm{i} v(\mathrm{t})
\end{aligned}
$$

and represents the motion of the point $z(t)$ on a perturbation of a circular orbit. The distance of this point from the centre of the orbit at time $\mathrm{t}$ is given by

$$
\gamma(\mathrm{t})=\left[\mathrm{u}^{2}(\mathrm{t})+\mathrm{v}^{2}(\mathrm{t})\right]^{\frac{1}{2}}=\left[1+(0.0005 \mathrm{t})^{2}\right]^{\frac{1}{2}}
$$

so that the point spirals slowly outwards as time increases.

Following Lambert and Watson [4] the differential equation is written in the form of the real linear system

$$
\begin{aligned}
& \mathrm{u}^{\prime \prime}=-\mathrm{u}+0.001 \cos \mathrm{t} ; \mathrm{u}(0)=1, \mathrm{u}^{\prime}(0)=0, \\
& \mathrm{v}^{\prime \prime}=-\mathrm{v}+0.001 \sin \mathrm{t} ; \mathrm{v}(0)=0, \mathrm{v}^{\prime}(0)=0.9995,
\end{aligned}
$$

from which the higher derivatives, for use with the multiderivative methods developed in section 1 , are easily determined. 
8.

The numerical solution $\mathrm{U}(\mathrm{t}), \mathrm{V}(\mathrm{t})$ of the real system (25) were computed at $\mathrm{t}=40 \pi$ for $\ell=\pi / 4, \pi / 5, \pi / 6, \pi / 9, \pi / 12$, using the multiderivative methods based on the $(2,2),(3,3)$ Pad $e^{\prime}$ approximants. The corresponding computed values $\mathrm{Z}(\mathrm{t}), \Gamma(\mathrm{t})$ of $\mathrm{z}(\mathrm{t}), \gamma(\mathrm{t})$ were then computed using

$$
\mathrm{z}(\mathrm{t})=\mathrm{U}(\mathrm{t})+\mathrm{iv}(\mathrm{t}) \quad, \quad \Gamma(\mathrm{t})=\left[\mathrm{U}^{2}(\mathrm{t})+\mathrm{V}^{2}(\mathrm{t})\right]^{\frac{1}{2}}
$$

The error moduli in the computed values $Z(t), \Gamma(t)$ given by

$$
\begin{aligned}
& \mathrm{E}(\mathrm{z}) \equiv|\mathrm{z}(\mathrm{t})-\mathrm{Z}(\mathrm{t})|=\left[\{\mathrm{u}(\mathrm{t})-\mathrm{U}(\mathrm{t})\}^{2}+\{\mathrm{v}(\mathrm{t})-\mathrm{V}(\mathrm{t})\}^{2}\right]^{\frac{1}{2}} \\
& \mathrm{E}(\gamma) \equiv|\gamma(\mathrm{t})-\Gamma(\mathrm{t})|=\left|\left\{\mathrm{u}^{2}(\mathrm{t})+\mathrm{v}^{2}(\mathrm{t})\right\}^{\frac{1}{2}}-\left\{\mathrm{U}^{2}(\mathrm{t})+\mathrm{V}^{2}(\mathrm{t})\right\}^{\frac{1}{2}}\right|
\end{aligned}
$$

were also calculated. The values of $\Gamma(\mathrm{t}), \mathrm{E}(\mathrm{z}), \mathrm{E}(\gamma)$ are given in Table 1.

It can be seen that for both methods tested, the path of the point $z(t)$ is an outward spiral for all steplengths, which is in keeping with the theoretical solution. The numerical solution obtained using the fourth order method based on the $(2,2)$ Pad $e^{\prime}$ approximant was found to be closer to the theoretical value $\gamma(40 \pi)$ than the method due to Cash [1], which is of comparable order, except for $\ell=\pi / 4$ when the error molulus was 0.002339 compared to 0.002146 obtained by Cash.

The computed solution obtained using the sixth order multiderivative method based on the $(3,3)$ Pad $e^{\prime}$ approximant was found to be closer to the theoretical solution $\gamma(40 \pi)$ than the sixth order methods of Lambert and Watson [4] or Cash [1]for all values of $\ell$. Moreover, convergence to six decimal places was attained for higher values of $\ell$ using the $(3,3)$ multiderivative method.

It is noted that the approximate formulas (22), (23) were used with the $(2,2),(3,3)$ Pad $e^{\prime}$ methods, respectively, whereas Cash [1] used the theoretical solution. 


\section{$\underline{\text { Problem } 2}$}

This example was used by Lambert and Watson [4] and Cash [1] and is given by

$$
\begin{aligned}
& \mathrm{y}_{1}^{\prime \prime}=-\mathrm{w}^{2} \mathrm{y}_{1}+\varphi^{\prime \prime}(\mathrm{t})+\mathrm{w}^{2} \varphi(\mathrm{t}) ; \mathrm{y}_{1}(\mathrm{o})=\mathrm{a}+\varphi(\mathrm{o}), \mathrm{y}_{1}^{\prime}(\mathrm{o})=\varphi^{\prime}(\mathrm{o}) \\
& \mathrm{y}_{2}^{\prime \prime}=-\mathrm{w}^{2} \mathrm{y}_{2}+\varphi^{\prime \prime}(\mathrm{t})+\mathrm{w}^{2} \varphi(\mathrm{t}) ; \mathrm{y}_{2}(\mathrm{o})=\varphi(\mathrm{o}), \mathrm{y}_{2}^{\prime}(\mathrm{o})=\mathrm{aw}+\varphi^{\prime}(\mathrm{o}) .
\end{aligned}
$$

The theoretical solution of the problem is given by

$$
\begin{aligned}
& \mathrm{y}_{1}(\mathrm{t})=\mathrm{a} \cos \mathrm{wt}+\phi(\mathrm{t}) \\
& \mathrm{y}_{1}(\mathrm{t})=\mathrm{a} \sin w \mathrm{t}+\phi(\mathrm{t})
\end{aligned}
$$

and, following Lambert and Watson [4] and Cash [1], $\phi(\mathrm{t})$ is taken to be $\mathrm{e}^{-0.05 t}$ The parameter a was given the value zero, corresponding to the case when high frequency oscillations are not present in the theoretical solution. The results at $\mathrm{t}=20 \pi$ for $\mathrm{w}=5(5) 40$ and $\ell=\pi / 32, \pi / 8, \pi / 2, \pi$ are given in Table 2 .

Comparing Table 2 with Table 2 in Cash [1], it is seen that, except in the isolated case $\mathrm{w}=5, \ell=\pi / 8$, the fourth order multiderivative method tested in the present paper gives better results than the fourth order method of Cash; the sixth order method tested in the present paper always gives superior results to the sixth order method in [1] when applied to Problem 2.

As with Problem 1, formulas (22), (23) were used to compute y( $\ell$ ). 


\section{Use in PECE mode}

In common with texts and other papers, the convention of associating an asterisk with a predictor formula will be adopted. Using the general $\left(0, \mathrm{k}^{*}\right)$ Pad $e^{\prime}$ approximant as predictor and the general $(\mathrm{m}, \mathrm{k}) \mathrm{Pad} e^{\prime}$ approximant as corrector, the resulting predictor-corrector combination will be denoted by $\left(0, \mathrm{k}^{*}\right) ;(\mathrm{m}, \mathrm{k})$.

It is not necessary to choose a predictor formula for which $\mathrm{k}^{*}=\max (\mathrm{m}, \mathrm{k})$ and the existing theory relating to the order of the local truncation error of linear multistep methods used in PECE mode carries over to multiderivative methods used in PECE mode. In particular, if the order of the predictor is at least the order of the corrector, than the error constant of the predictor-corrector combination is that of the corrector alone. In addition, if the predictor and the corrector have the same order $\mathrm{p}$, then Milne's device

$$
\mathrm{C}_{\mathrm{p}+2}\left[\mathrm{y}_{\mathrm{n}+1}^{(\mathrm{c})}-\mathrm{y}_{\mathrm{n}+1}^{(\mathrm{p})}\right] /\left[\mathrm{C}_{\mathrm{p}+2}^{*}-\mathrm{C}_{\mathrm{p}+2}\right]
$$

may be used to estimate the error constant of the predictor-corrector combination in PECE mode (provided $\mathrm{C}_{\mathrm{p}+2}^{*} \neq \mathrm{C}_{\mathrm{p}+2}$ ). In (26) the superscripts (P) and (C) refer to the predictor and corrector, respectively.

The periodicity polynomial $\Omega_{\mathrm{PECE}}\left(\mathrm{r}, \mathrm{H}^{2}\right)$ of the $\left(0, \mathrm{k}^{*}\right) ;(\mathrm{m}, \mathrm{k})$ combination in PECE mode may be shown to take the form

$$
\begin{aligned}
& \Omega_{\text {PECE }}\left(r, H^{2}\right)=r^{2}-\left[2-2 \sum_{j=1}^{m}(-1)^{j_{a}} H^{2 j}+\sum_{j=1}^{s}(-1) b_{j} H^{2 j}\right. \\
& \left.+\sum_{j=1}^{m}(-1) \mathrm{j}_{\mathrm{j}} \mathrm{H}^{2 \mathrm{j}} \quad \sum_{\mathrm{w}=1}^{\delta^{*}}(-1)^{\mathrm{w}} \mathrm{b}_{\mathrm{w}}^{*} \mathrm{H}^{2 \mathrm{w}}\right] \mathrm{r}+1
\end{aligned}
$$


The interval of periodicity of the $\left(0, \mathrm{k}^{*}\right) ;(\mathrm{m}, \mathrm{k})$ predictor-corrector combination is determined by computing the values of $\mathrm{H}$ for which the zeros of the periodicity equation

$$
\Omega_{\mathrm{PECE}}\left(\mathrm{r}, \mathrm{H}^{2}\right)=0
$$

satisfy (22).

It was found that the $(0,2) ;(1,2)$ combination, with error constant $\mathrm{C}_{4}=-\frac{1}{36}$ and periodicity interval $\mathrm{H}^{2} \in(0,9)$, has the smallest modulus error constant and the greatest interval of periodicity of the second order combinations.

Of the fourth order combinations, it was found that the $(0,4) ;(2,2)$ combination, for which $\mathrm{C}_{6}=\frac{1}{360}$ and $\mathrm{H}^{2} \in(0,15.89)$, is to be preferred to any other fourth order combination when solving non-linear problems, because it requires no more than the second derivative of $\underset{\sim}{\mathrm{f}}(\mathrm{t}, \underset{\sim}{\mathrm{y}})$.

For linear problems the $(0,4) ;(1,3)$ combination which has $\mathrm{C}_{6}=\frac{-7}{2880}$ and $\mathrm{H}^{2} \in(0,4.88)$, may be used with small values of $\ell$ if higher accuracy is needed.

For non-linear problems of the form (1) the maximum steplength which may be used at any time $t$ of the calculation, has the value $H^{*} / \Lambda(t)$, where $\mathrm{H}^{2} \in\left(0, \mathrm{H}^{*}\right)$ is the periodicity interval of the predictorcorrector combination being used, and $\Lambda^{2}(\mathrm{t})$ is the largest modulus real part of the eigenvalues of the Jacobian $\underset{\sim}{\mathrm{f}} / \partial \underset{\sim}{\mathrm{y}}$ at time $\mathrm{t}$.

The $(0,4) ;(2,2)$ method was tested on the following problem which was discussed in Shampine and Gordon [5] and Jain et al [2]:

Problem 3

$$
\begin{aligned}
& x^{\prime \prime}=\frac{x}{r^{3}} ; x(0)=1, x^{\prime}(0)=0 \\
& y^{\prime \prime}=-\frac{y}{r^{3}} ; y(0)=0, y^{\prime}(0)=1
\end{aligned}
$$


where $r=\left(x^{2}+y^{2}\right)^{\frac{1}{2}}$. These equations are Newton's equations of motion for the two body problem and the initial conditions are such that the motion is circular. Clearly $x^{\prime \prime}(0)=-1, y^{\prime \prime}(0)=0$ and, by successively differentiating the expressions for $x^{\prime \prime}$ and $y "$, it is easy to verify that $\mathrm{x}(\mathrm{t})$ and its derivatives take the values $1,0,-1,0$ cyclically at $\mathrm{t}=0$, and that $\mathrm{y}(\mathrm{t})$ and its derivatives take the values $0,1,0,-1$ cyclically at $\mathrm{t}=0$. Taylors series, with sufficiently small stepsizes, provides starting values for the following strategy where, for $\mathrm{n}=1,2, \ldots,{\underset{\sim}{\mathrm{n}}}_{\mathrm{n}}=\left[\mathrm{x}_{\mathrm{n}}, \mathrm{y}_{\mathrm{n}}\right]^{\mathrm{T}}=[\mathrm{x}(\mathrm{n} \ell), \mathrm{y}(\mathrm{n} \ell)]^{\mathrm{T}}$ :

$\mathrm{P}: \quad \underset{\sim}{\mathrm{W}+1}(\mathrm{P})$ is calculated using, as predictor, the multiderivative method based on the $(0,4)$ Pad $e^{\prime}$ approximant;

$\mathrm{E}: \quad$ (a) ${\underset{\sim}{\mathrm{w}}}_{\mathrm{n}+1}^{\prime}$ is evaluated using $\underset{\sim}{\mathrm{w}}{ }_{\mathrm{n}+1}^{\prime}=\frac{1}{\ell} \sum_{\mathrm{m}=1}^{6} \nabla{\underset{\sim}{\mathrm{w}}}_{\mathrm{n}+1}^{(\mathrm{P})} / \mathrm{m}+0\left(\ell^{6}\right)$, where $\nabla$ is the usual backward difference operator,

(b) $\stackrel{\underset{w}{\sim}}{\sim} \mathrm{n+1}$ is evaluated using $\underset{\sim}{\mathrm{w}} \underset{\mathrm{n}+1}{(\mathrm{P})}$ in the system of differential equations,

(c) $\underset{\sim}{\mathrm{W}}(\mathrm{iv})$ is evaluated from the analytical expressions for $x_{n+1}^{(i v)}, y_{n+1}^{(i v)}$ which are easily determined (these contain $\mathrm{x}_{\mathrm{n}+1}^{\prime}, \mathrm{y}_{\mathrm{n}+1}^{\prime}$

C: $\quad \mathrm{W}_{\sim}^{(\mathrm{C})}$ is calculated using, as corrector, the multiderivative method based on the $(2,2)$ Pad $e^{\prime}$ approximant;

E: $\quad \mathrm{W}_{\sim \mathrm{n}+1}^{\prime}, \mathrm{W}_{\sim}^{\prime \prime}{ }_{\mathrm{n}+1} \mathrm{~W}_{\sim}^{(\mathrm{iv})}{ }_{\mathrm{n}+1}$ are re-evaluated as in $(\mathrm{a}),(\mathrm{b}),(\mathrm{c})$ above using the corrected value $\mathrm{W}_{\sim}^{(\mathrm{c})}$ where appropriate.

The problem was tested using $\ell=\pi / 18, \pi / 15, \pi / 10$ and the numerical solution at time $\mathrm{t}=12 \pi$ determined using the $(0,4) ;(2,2)$ combination in PECE mode. Using the theoretical solution $x(t)=\cos t, y(t)=\operatorname{sint}$ the error moduli for the three values of $\ell$ are easily found and are 
given in Table 3 . Results are also tabulated using the $(0,4)$ method alone. Comparison with Table 1 in Jain et al [2] shows that multiderivative methods give accurate numerical results for non-linear as well as linear problems.

\section{$\underline{\text { Problem } 4}$}

Changing the initial conditions in Problem 3 to

$$
\begin{aligned}
& \mathrm{x}(0)=0.4, \mathrm{x}^{\prime}(0)=0, \\
& \mathrm{y}(0)=0, \mathrm{y}^{\prime}(0)=2,
\end{aligned}
$$

causes the orbit to become the ellipse (Shampine and Gordon [5:p.245])

$$
\mathrm{r} \equiv(\mathrm{x}+0.6)^{2}+\mathrm{y}^{2} / 0.64=1
$$

and the period of revolution to be $2 \pi$. The problem was tested with $\ell=\pi / 45, \pi / 90, \pi / 180, \pi / 360, \pi / 720$ and the value of $r$ at time $\mathrm{t}=15 \pi, 16 \pi$ determined using the $(0,2) ;(2,2)$ combination in PECE mode. The values of $\mathrm{x}, \mathrm{y}, \mathrm{r}$ (theoretical values $0.4,0,1$ and $-1.6,0,1$, respectively) are given at time $\mathrm{t}=15 \pi, 16 \pi$ in Table 4 . It is again clear that the multiderivative predictor-corrector combination used gives accurate results. Unlike the method used and reported in Shampine and Gordon [5: p.246], no step size or order changing was required to achieve the accuracy obtained using the multiderivative methods. 
Table 1

Computed results at $\mathrm{t}=40 \pi$ for Pro blem 1 .

$\gamma(40 \pi)=1.001972 \quad, \quad \mathrm{u}(40 \pi)=1 \quad, \quad \mathrm{v}(40 \pi)=-0.062832$

\begin{tabular}{|c|c|c|c|c|c|c|}
\hline \multirow{2}{*}{$\ell$} & \multicolumn{3}{|c|}{$(2,2)$ method } & \multicolumn{3}{c|}{$(3,3)$ method } \\
\cline { 2 - 7 } & $\Gamma$ & $\mathrm{E}(\gamma)$ & $\mathrm{E}(\mathrm{z})$ & $\Gamma$ & $\mathrm{E}(\gamma)$ & $\mathrm{E}(\mathrm{z})$ \\
\hline$\pi / 4$ & 1.004311 & $0.234(-2)$ & $0.418(-2)$ & 1.001981 & $0.908(-5)$ & $0.813(-7)$ \\
$\pi / 5$ & 1.002845 & $0.874(-3)$ & $0.710(-3)$ & 1.001974 & $0.236(-5)$ & $0.567(-8)$ \\
$\pi / 6$ & 1.002383 & $0.411(-3)$ & $0.167(-3)$ & 1.001972 & $0.792(-6)$ & $0.642(-9)$ \\
$\pi / 9$ & 1.002052 & $0.805(-4)$ & $0.659(-5)$ & 1.001972 & $0.699(-7)$ & $0.501(-11)$ \\
$\pi / 12$ & 1.001997 & $0.255(-4)$ & $0.664(-6)$ & 1.001972 & $0.125(-7)$ & $0.159(-12)$ \\
\hline
\end{tabular}


Table 2

Error modulus in the computed solution at $\mathrm{t}=20 \Pi$ for Problem 2 .

\begin{tabular}{|c|c|c|c|c|}
\hline $\mathrm{W}$ & $\pi / 32$ & $\pi / 8$ & $\pi / 2$ & $\pi$ \\
\hline \multicolumn{5}{|c|}{$(2,2)$ multiderivative method } \\
\hline 5 & $0.402(-15)$ & $0.103(-12)$ & $0.194(-10)$ & $0.200(-9)$ \\
\hline 10 & $0.994(-16)$ & $0.885(-13)$ & $0.139(-11)$ & $0.115(-11)$ \\
\hline 15 & $0.119(-15)$ & $0.101(-14)$ & $0.183(-12)$ & $0.144(-10)$ \\
\hline 20 & $0.879(-16)$ & $0.502(-14)$ & $0.858(-12)$ & $0.359(-11)$ \\
\hline 25 & $0.428(-16)$ & $0.254(-14)$ & $0.522(-12)$ & $0.519(-11)$ \\
\hline 30 & $0.310(-15)$ & $0.752(-15)$ & $0.246(-12)$ & $0.390(-11)$ \\
\hline 35 & $0.502(-15)$ & $0.715(-15)$ & $0.261(-12)$ & $0.265(-11)$ \\
\hline 40 & $0.176(-15)$ & $0.782(-15)$ & $0.251(-13)$ & $0.179(-11)$ \\
\hline \multicolumn{5}{|c|}{$(3,3)$ multiderivative method } \\
\hline 5 & $0.185(-15)$ & $0.953(-15)$ & $0.340(-11)$ & $0.182(-12)$ \\
\hline 10 & $0.166(-15)$ & $0.116(-14)$ & $0.231(-14)$ & $0.264(-14)$ \\
\hline 15 & $0.118(-15)$ & $0.795(-16)$ & $0.946(-17)$ & $0.576(-15)$ \\
\hline 20 & $0.423(-16)$ & $0.885(-16)$ & $0.380(-16)$ & $0.189(-15)$ \\
\hline 25 & $0.319(-15)$ & $0.480(-17)$ & $0.102(-16)$ & $0.119(-16)$ \\
\hline 30 & $0.290(-15)$ & $0.600(-18)$ & $0.522(17)$ & $0.256(-16)$ \\
\hline 35 & $0.138(-15)$ & $0.491(-18)$ & $0.261(-17)$ & $0.137(-16)$ \\
\hline 40 & $0.271(-16)$ & $0.261(-18)$ & $0.183(-17)$ & $0.309(-17)$ \\
\hline
\end{tabular}


Table 3

Error moduli at $\mathrm{t}=12 \pi$ for Problem 3

\begin{tabular}{|c|c|c|}
\hline & $(0,4)$ method & $\begin{array}{c}(0,4) ;(2,2) \\
\text { Combination }\end{array}$ \\
\hline$\ell$ & Error moduli & Error moduli \\
$\pi / 18$ & $0.394(-7)$ & $0.665(-8)$ \\
$\pi / 15$ & $0.209(-6)$ & $0.298(-7)$ \\
$\pi / 10$ & $0.650(-5)$ & $0.120(-5)$ \\
\hline
\end{tabular}


$\underline{\text { Table } 4}$

Computed values of $\mathrm{x}, \mathrm{y}, \mathrm{r}$ at $\mathrm{t}=15 \pi, 16 \pi$ for Problem 4

\begin{tabular}{|lccc|}
\hline & $\mathrm{x}$ & $\mathrm{y}$ & $\mathrm{r}$ \\
$\mathrm{t}=15 \pi$ & & & \\
$\pi / 45$ & & & \\
$\pi / 90$ & -1.6003845 & 0.0244339 & 1.0017020 \\
$\pi / 180$ & -1.5997948 & 0.0010838 & 0.9995914 \\
$\pi / 360$ & -1.5999258 & -0.0001281 & 0.9998517 \\
$\pi / 720$ & -1.5999801 & -0.0000584 & 0.9999603 \\
$\mathrm{t}=16 \pi$ & -1.5999950 & -0.0000163 & 0.9999899 \\
$\pi / 45$ & & & \\
$\pi / 90$ & & & 0.9999049 \\
$\pi / 180$ & 0.3999265 & 0.0057571 & 1.0000826 \\
$\pi / 360$ & 0.3995450 & 0.0252020 & 1.0000070 \\
$\pi / 720$ & 0.3999516 & 0.0081528 & 1.0000005 \\
\hline
\end{tabular}




\section{$\underline{\text { References }}$}

1. J. R. Cash. High order P-stable formulae for the numerical integration of periodic initial value problems. Numer. Math., 37(1981). pp.355-370.

2. M. K. Jain, R. K. Jain and U. A. Krishnaiah. P-stable methods for periodic initial value problems of second order differential equations. BIT, 19(1979).pp.347-355.

3. J. D. Lambert. Computational Methods in Ordinary Differential Equations. John Wiley and Sons, Chichester, 1973.

4. J. D. Lambert and I. A. Watson. Symmetric multistep methods for periodic initial value problems. J. Inst. Maths. Applics., 18 (1976) pp. 189-202.

5. L. F. Shampine and M. K. Gordon. Computer Solution of Ordinary Differential Equations. W. H. Freeman and Company, San Francisco, 1973.

6. E. Stiefel and D. G. Bettis. Stabilization of Cowell's methods. Numer. Math., 13 (1969). pp.154-175.

7. E. H. Twizell. TR/92. Brunel University Department of Mathematics Technical Report (1980).

8. E. H. Twizell. TR/l3/81. Brunel University Department of Mathematics Technical Report (1981).

9. E. H. Twizell and A. Q. M. Khaliq. One-step multiderivative methods for first order ordinary differential equations. BIT, 21 (1981). pp.518-527. 


\section{$\underline{\text { Appendix }}$}

The non-zero constants $a_{j}(j=1, \ldots, m), b_{w}(w=1, \ldots, s)$ for the first sixteen entries of the Pad $e^{\prime}$ Table for the exponential function, together with the error constants and the intervals of periodicity.

$(0,1):$ All $a_{j}=0 ;$ all $b_{w}=0$.

$\mathrm{C}_{2}=1$ (method inconsistent).

$(1,1): a_{1}=-\frac{1}{4} ; b_{1}=\frac{1}{2}$.

$\mathrm{C}_{4}=-\frac{1}{6} ; \mathrm{H}^{2} \in(0, \infty)$.

$(1,0): a_{1}=-1 ;$ all $b_{w}=0$.

$\mathrm{C}_{2}=-1$ (method inconsistent).

$(0,2): \quad$ All $a_{j}=0 ; b_{1}=1$.

$\mathrm{C}_{4}=\frac{1}{12} ; \mathrm{H}^{2} \in(0,4) \ldots$

$(1,2): \mathrm{a}_{1}=-\frac{1}{9} ; \mathrm{b}_{1}=\frac{7}{9}$.

$\mathrm{C}_{4}=-\frac{1}{36} ; \mathrm{H}^{2} \in\left(0, \frac{36}{5}\right)$.

$(2,2): a_{1}=-\frac{1}{12}, a_{2}=\frac{1}{144} ; b_{1}=\frac{5}{6}, b_{2}=\frac{1}{72}$.

$\mathrm{C}_{6}=\frac{1}{360} ; \mathrm{H}^{2} \in(0, \infty)$.

$(2,1): \mathrm{a}_{1}=-\frac{1}{9}, a_{2}=\frac{1}{36} ; b_{1}=\frac{7}{9}$.

$\mathrm{C}_{4}=\frac{1}{36} ; \mathrm{H}^{2} \in(0, \infty)$.

$(2,0): a_{2}=-\frac{1}{4}, ; b_{1}=1$.

$\mathrm{C}_{4}=\frac{7}{12} ; \mathrm{H}^{2} \in(0, \infty)$.

$(0,3):$ All $a_{j}=0 ; b_{1}=1$

$\mathrm{C}_{4}=\frac{1}{12} ; \mathrm{H}^{2} \in(0,4)$. 


$$
\begin{aligned}
& (1,3): a_{1}=-\frac{1}{16} ; b_{1}=\frac{7}{8}, b_{2}=\frac{1}{48} \text {. } \\
& \mathrm{C}_{6}=-\frac{7}{2880} ; \mathrm{H}^{2} \in(0,6.5) \text { and }(29.5 .48) \text {. } \\
& (2,3): a_{1}=-\frac{3}{50} ; a_{2}=\frac{1}{400}, b_{1}=\frac{22}{25}, b_{2}=\frac{17}{600} \text {. } \\
& \mathrm{C}_{6}=-\frac{1}{3600} ; \mathrm{H}^{2} \in(0,8.2) \text { and }\left(14 \cdot 6 \cdot \frac{300}{7}\right) \text {. } \\
& (3,3): a_{1}=-\frac{1}{20} ; a_{2}=\frac{1}{600}, a_{3}=\frac{1}{14400} ; . \\
& \mathrm{b}_{1}=-\frac{9}{10} ; \mathrm{b}_{2}=\frac{11}{330}, \mathrm{~b}_{3}=\frac{1}{7200} \text {. } \\
& \mathrm{c}_{8}=-\frac{1}{50400} ; \mathrm{H}^{2} \in(0, \infty) \text {. } \\
& (3,2): a_{1}=-\frac{3}{50} ; a_{2}=\frac{1}{400}, a_{3}=\frac{1}{3600} ; \\
& \mathrm{b}_{1}=-\frac{22}{25} ; \mathrm{b}_{2}=\frac{17}{600} \text {. } \\
& \mathrm{c}_{6}=-\frac{1}{3600} ; \mathrm{H}^{2} \in(0, \infty) \text {. } \\
& (3,1): a_{1}=-\frac{1}{16} ; a_{3}=-\frac{1}{576}, b_{1}=\frac{7}{8}, b_{2}=\frac{1}{48} \text {. } \\
& \mathrm{C}_{6}=-\frac{17}{2880} ; \mathrm{H}^{2} \in(0, \infty) \text {. } \\
& (3,0): a_{1}=-\frac{1}{12} ; a_{3}=-\frac{1}{36}, b_{1}=1 \text {. } \\
& \mathrm{C}_{4}=-\frac{1}{12} ; \mathrm{H}^{2} \in(0, \infty) \text {. } \\
& (0,4): \text { All } a_{j}=-0 ; b_{1}=1, b_{2}=\frac{1}{12} \text {. } \\
& \mathrm{C}_{6}=-\frac{1}{360} ; \mathrm{H}^{2} \in(0,12) \text {. }
\end{aligned}
$$

